Approach To ensure the service was responsive and effective the Duty CNS, who provides a first response telephone service, and the Urgent Response Nurse would work closely together. The majority of Urgent Response referrals were from the Duty CNS following an identified need. The Hospice@ Home service allocates a Band 5/6 nurse each day to carry out Urgent Response visits. Each visit involves a holistic assessment and management of urgent concerns and problems. Outcome Following a three month pilot an audit of the 30 patients referred was carried out. 95\% of the visits were carried out within two hours of referral. The service:

- Supported patients in crisis to remain at home

- Assessed and managed symptoms

- Identified patients with palliative care emergencies and facilitated admission

- Supported patients and families in emotional distress

- Carried out urgent assessment/review.

Direct feedback from patients, relatives and colleagues was extremely positive highlighting that the service provided timely, effective and supportive care.

Conclusion Due to the audit results and positive impact of the service the pilot was extended and the service continues. In addition the service facilitated more effective working relationships and team integration between $\mathrm{H} @ \mathrm{H}$ and the CNS team.

\section{P-157 CINDERELLA SERVICE - IMPROVING CARE AT HOME WITH THE GSF DOMICILIARY CARE PROGRAMME}

Keri Thomas. The National GSF Centre for End of Life Care, London, UK

\subsection{6/bmispcare-2018-hospiceabs. 182}

Aim Domiciliary care workers play an important but often unrecognised role in supporting people to remain at home as they near the end of life, especially those with dementia and frailty. Despite this, few receive specific training in end of life care. Focussed training enables home care workers to improve the quality of care for such people who choose to remain in their homes, and contribute to better coordinated cross boundary care.

Method The fully revised GSF Domiciliary Care training programme focuses on enabling generalist frontline staff in end of life competencies. The Train-the-Trainer cascade programme works with Domiciliary Care Agency Trainers; using action based, interactive learning and reflective practice in six modules, with support from the virtual learning Zone/DVD, and resources. Comparative before and after qualitative and quantitative evaluation is intrinsic and includes frontline care worker confidence self-assessments, supportive care analyses and organisational competency questionnaires.

Results Homecare workers in various areas of the country show improvements in:

- Confidence and competence of home care staff

- Communication, working relationships and collaboration with primary care

- More advance care planning discussions, with service users keen to be involved in these discussions

- Encouragement and empowerment of staff to advocate for their service users leading to improved communications with other professionals

- Increased awareness of the knowledge they already possessed and future training needs.
Conclusion This highlights the important role that domiciliary care workers play, and the importance of empowering care staff that interact with the service users on a daily basis. The GSF Domiciliary Care Training Programme boosts the confidence and competence of care workers, improves collaboration and coordination with others and helps to improve care for more people nearing the end of life at home - which is for most the best place to be.

\section{P-158 INCREASING THE RESPONSIVENESS OF THE COMMUNITY CLINICAL NURSE SPECIALIST TEAM}

Melanie Holmes, Andrew Fletcher, Simon Walker. St Catherine's Hospice, Preston, UK

\subsection{6/bmjspcare-2018-hospiceabs.183}

Background Referrals to the community team are increasing and demand for community palliative care services has led to a longer community waiting list. Consequently, the hospice is struggling to respond quickly to referrals for community assessment. In 2016/2017, 200 patients died whilst waiting to be seen.

Aims To reduce the time from referral to initial palliative care assessment for patients who have un-managed symptoms at the point of referral. To reduce the number of patients who die before being seen by specialist palliative care. To reduce unnecessary emergency hospital admissions. To support earlier discharge from hospital. To facilitate appropriate hospice IPU admissions in a timelier manner. To reduce the need to contact the GP or district nurse (DN). To reduce on-going distress of the patient/family member/carer. To create a positive experience for the patient/family member/carer.

Methods The new way of working involved creating capacity in order that a Clinical Nurse Specialist was able to respond in a timely way to patients who have been deemed to need an urgent response due to un-managed symptoms or an expected short prognosis. The urgent response role was intended to have minimal caseload responsibilities, having the capacity to be responsive.

Results The project data extracted was in three phases: (1). 12 weeks pre-project; (2). 12 weeks with an additional 1.0 WTE working as an urgent response nurse; (3). 12 weeks without additional capacity having a substantive CNS working in an urgent response way. The results showed that the different way of working increased the number of assessments completed and the numbers of patients that died before being seen reduced considerably, whilst increasing the number of active patients on caseloads. The project produced positive data that working in a different way could improve responsiveness, but additional capacity improved outcomes even further.

\section{P-159 USING EXISTING RESOURCES TO ENHANCE COMMUNITY PALLIATIVE CARE: 30 MINUTES TO MAKE A DIFFERENCE}

'Laura Edwards, ${ }^{2}$ Sarah Hussey, ${ }^{1}$ Suzanne Lomax, ${ }^{3}$ jill Pinington. ${ }^{1}$ Bolton NHS Foundation Trust, Bolton, UK; ${ }^{2}$ Bolton Hospice, Bolton, UK; ${ }^{3}$ Bolton NHS Foundation Trust, Bolton, UK

\subsection{6/bmjspcare-2018-hospiceabs. 184}

Background Bolton NHS Foundation Trust serves a population of approximately 260,000. Specialist palliative care services are integrated between hospital, community and 